\title{
Trends in excess of weight, underweight and adiposity among Spanish children from 2004 to 2010: the Cuenca Study
}

\author{
Vicente Martínez-Vizcaíno 1,2,* , Montserrat Solera Martínez ${ }^{1}$, Blanca Notario Pacheco ${ }^{1}$, \\ Mairena Sánchez López ${ }^{1}, 3$, Jorge Cañete García-Prieto ${ }^{1}$, Coral Torrijos Niño ${ }^{1}$, \\ Natalia Arias Palencia' ${ }^{1}$, Fernando Salcedo Aguilar ${ }^{4}$ and Fernando Rodríguez-Artalejo ${ }^{5,6}$ \\ 'Social and Health Care Research Center, University of Castilla-La Mancha, Edificio Melchor Cano, Calle Santa \\ Teresa Jornet s/n, E-16071 Cuenca, Spain: ${ }^{2}$ Research Network on Preventive Activities and Health Promotion \\ (redIAPP), Cuenca, Spain: ${ }^{3}$ School of Education, University of Castilla-La Mancha, Ciudad Real, Spain: ${ }^{4}$ Family \\ and Community Medicine Teaching Unit, Servicio de Salud de Castilla-La Mancha, Cuenca, Spain: ${ }^{5}$ Department \\ of Preventive Medicine and Public Health, School of Medicine, Universidad Autónoma de Madrid, Madrid, \\ Spain: ${ }^{6} \mathrm{CIBER}$ in Epidemiology and Public Health (CIBERESP), Madrid, Spain
}

Submitted 11 July 2011: Final revision received 31 January 2012: Accepted 17 June 2012: First published online 27 July 2012

\begin{abstract}
Objective: To examine the trends in BMI and adiposity among schoolchildren from Cuenca, Spain, during 2004-2010.

Design: Two methodologically comparable surveys were carried out in 2004 and 2010.

Setting: Primary schools in Cuenca, a province in the middle of Spain.

Subjects: All schoolchildren aged 8-11 years, belonging to 4th and 5th grades from twenty schools in the Province of Cuenca, were invited to participate in both cross-sectional studies. Weight, height and body fat percentage (BF\%) from bioelectrical impedance were measured with standardized procedures.

Results: The study included 550 boys and 539 girls in 2004, and 569 boys and 531 girls in 2010 . In $2010,8 \cdot 1 \%$ of children were underweight, $25 \cdot 9 \%$ overweight and $9.5 \%$ obese. From 2004 to 2010, the prevalence of overweight rose from $21.6 \%$ to $28.0 \%(P=0.004)$ and $\mathrm{BF} \%$ increased from $22.6 \%$ to $24 \cdot 0 \%(P=0.001)$ among boys. No change was observed in overweight and $\mathrm{BF} \%$ in girls, or in underweight and obesity in either sex. In boys, most of the distribution of BMI and $\mathrm{BF} \%$ shifted to the right; in contrast, among girls no substantial change was apparent in the distribution of BMI and $\mathrm{BF} \%$.

Conclusions: From 2004 to 2010 the prevalence of overweight and adiposity has continued to increase among boys. However, the obesity epidemic may have levelled off in girls. Given that the prevalence of childhood excess weight is still very high, the current evidence-based efforts to halt the obesity epidemic in Spain should be strengthened.
\end{abstract}

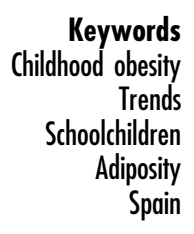

Childhood obesity is a worldwide public health problem ${ }^{(1)}$. The prevalence of overweight and obesity in children from the Province of Cuenca ${ }^{(2)}$ is similar to that reported in other Spanish studies ${ }^{(3)}$, but slightly lower than in children from the south of Spain and the Canary Islands ${ }^{(4)}$. In the European context, Spanish figures are similar to those in children from most southern European countries ${ }^{(1)}$; Australian and US children have similar prevalence figures, and a plateau has been reported in the trends of both countries $^{(5,6)}$. In Spain, although due to the magnitude of the problem has launched initiatives to tackle it ${ }^{(7)}$, no studies have been published on recent trends in childhood obesity.

Although obesity has been defined as excess accumulation of body fat sufficiently high to create health risk $^{(8)}$, most population-based data on the prevalence of obesity have relied on the BMI, a surrogate measure not as strongly associated with cardiometabolic risk in children ${ }^{(9)}$. Increased adiposity has been observed in children for whom BMI mean remained stable ${ }^{(10)}$. Furthermore, an increase in the obesity prevalence, as indicated from higher BMI, may not necessarily result from an increase in body fat, particularly in population subgroups which have augmented their physical activity over time ${ }^{(11,12)}$. To our knowledge, studies examining simultaneously the trends in overweight and adiposity in population-based samples of children in Europe are scarce ${ }^{(10,13)}$. There is abundant information on the childhood obesity epidemic, but in developed countries trends in overweight and thinness among children are very seldom described jointly ${ }^{(14,15)}$. 
To our knowledge, the Cuenca Study is the first on schoolchildren in a Mediterranean country which simultaneously examines the trends in overweight and thinness in the last two decades ${ }^{(16)}$.

Accordingly, the present work has examined the trends in BMI and adiposity among schoolchildren from Cuenca, Spain, over the period 2004-2010.

\section{Materials and methods}

\section{Study design and population}

Data were taken from two methodologically similar crosssectional surveys conducted in 2004 and 2010 among schoolchildren aged 8-11 years in 4th and 5th grades from twenty public schools in the Province of Cuenca. Of these twenty schools, nineteen were located in the most populated towns in the province and the other one was situated in the City of Cuenca. The Province of Cuenca is located in the middle of Spain; the predominant socioeconomic level is low-medium, and approximately $85 \%$ of the child population is living in the studied towns.

Both surveys were approved by the Clinical Research Ethics Committee of the 'Virgen de la Luz' Hospital in Cuenca. They were also approved by the Director and Board of Governors (Consejo Escolar) of each school. For data collection, parents gave written consent to the participation of their children in the study, and children gave verbal consent when, in informative talks held class-by-class, they were asked to collaborate. After the data were obtained, the parents were informed by letter of their children's results.

\section{Study variables}

Anthropometry and adiposity

Methods for data collection were identical in both surveys and have been reported elsewhere ${ }^{(2,16)}$. Briefly, for weight we calculated the mean of two readings from a digital scale (100 g accuracy) with children lightly dressed and without shoes. Height was assessed as the mean of two measures taken with a wall-mounted height rod on shoeless children standing straight against the wall, so that their spine was vertically aligned with the centre of the height rod. The head was placed with the chin parallel to the floor, and height was measured to the nearest millimetre. BMI was calculated as weight in kilograms divided by the square of the height in metres.

In both studies adiposity was assessed as body fat percentage ( $\mathrm{BF} \%)$, estimated by bioelectrical impedance using the BC-418MA Tanita Segmental Body Composition Analyser (Tanita Corp., Tokyo, Japan). We calculated a mean of two readings obtained in the morning, under controlled temperature and humidity conditions, with the child being shoeless and fasting, and after urination and a 15 min rest.
In the two cross-sectional surveys, the measurements were obtained at the schools by trained and certified nurses.

\section{Statistical analysis}

Children were classified as underweight, normal weight, overweight and obese according to the BMI cut-offs proposed by the International Obesity Taskforce ${ }^{(17,18)}$. Differences in the frequency of each BMI category between 2004 and 2010 were assessed with the $\chi^{2}$ test. For BMI and BF\% differences were analysed with an unpaired $t$ test. Analyses were performed with the statistical software package IBM SPSS Statistics 19 and statistical significance was set at two-tailed $P \leq 0 \cdot 05$.

For graphical comparisons of $\mathrm{BMI}$ and $\mathrm{BF} \%$, their frequency distributions were smoothed with kernel density estimation for univariate data ${ }^{(19)}$ using the STATA statistical software package version 8 .

\section{Results}

In the 2004 survey, 1409 children were invited and 1119 (79.4\%) accepted to participate. Corresponding figures for the 2010 survey were 1596 and 1070 (67.0\%). The proportion of boys and girls in each study was approximately $50 \%$, with no statistically significant differences in age between the sexes.

In $2004,9 \cdot 4 \%$ of children were underweight, $22 \cdot 2 \%$ overweight and $9.3 \%$ obese; in 2010, these figures were respectively $8 \cdot 1 \%, 25 \cdot 9 \%$ and $9 \cdot 5 \%$. The prevalence of overweight was higher in boys than in girls. BF \% in 2010 was $24.0 \%$ and $26.7 \%$ in boys and girls, respectively, thus higher in girls than in boys (Table 1 ).

From 2004 to 2010, the prevalence of overweight rose from $21 \cdot 6 \%$ to $28.0 \%(P=0.004)$ and $\mathrm{BF} \%$ increased from $22 \cdot 6 \%$ to $24 \cdot 0 \%(P=0 \cdot 001)$ among boys. However, no statistically significant change was observed in overweight and $\mathrm{BF} \%$ in girls, or in underweight and obesity in either sex, over the period 2004-2010 (Table 1).

The smoothed frequency distributions of BMI and BF \% at the two time points are compared in Fig. 1. In boys, most of the distribution of BMI and $\mathrm{BF} \%$ shifted to the right from 2004 to 2010, thus the levels of BMI and BF \% have increased in this period time. In contrast, among girls no substantial change in the distribution of BMI and $\mathrm{BF} \%$ was observed over the study period.

\section{Discussion}

From 2004 to 2010 in Cuenca, the prevalence of overweight and adiposity has continued to increase among boys. However, the obesity epidemic may have levelled off in girls. The underweight prevalence did not change significantly in this period. Lastly, BF \% increased significantly only in boys. 


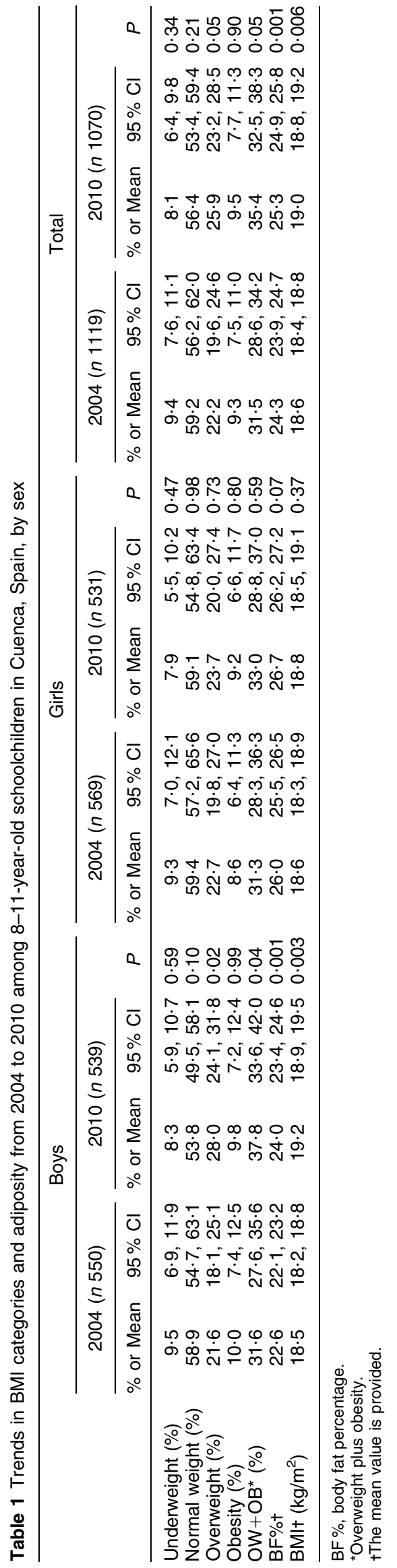

A levelling off of the obesity epidemic in 2-12-year-old children in Australia, Japan, USA and many European countries has recently been reported ${ }^{(20)}$. However, we have found no evidence of a halt of the epidemic in male schoolchildren in Cuenca, despite the implementation of some promising initiatives to tackle this health disorder in Spain ${ }^{(7)}$. Changes in the distribution of BMI over time were in line with the shift in the distribution of $\mathrm{BF} \%$. Both $\mathrm{BMI}$ and $\mathrm{BF} \%$ increased in the period 2004-2010, but significantly so only in boys. This indicates that the main driver of increased overweight registered in boys was an increase of adiposity. Unfortunately, the specific factors responsible for the continuing increase in overweight among children in Cuenca are poorly understood. As the time frame of our study was too short, it is inconceivable that genetic or epigenetic factors are involved. Nevertheless, these trends could be related to the so-called 'obesogenic environment', which usually refers to societal or environmental changes that promote or discourage behaviours such as excess consumption of energy-dense foods and beverages or screen time of watching television and playing digital games ${ }^{(21-23)}$.

There are notable differences between the distributions of childhood BMI and BF \% in Cuenca and the USA, since they have only moderate skewness in Spanish children but are very skewed to the right in US children $^{(24)}$. Therefore, although the prevalence of overweight plus obesity in Spanish children may seem very high, the frequency of extreme obesity is lower than in the USA.

In addition to in Spain ${ }^{(25)}$, sex differences in obesity trends have been reported in several countries. In Sweden, the prevalence of obesity has recently increased slightly in boys but decreased in girls ${ }^{(26,27)}$. In England, trends in obesity levelled off in boys and decreased in girls aged $2-10$ years in the period $1995-2007^{(28)}$. Moreover, in the USA the trends in excess of weight are worse for boys than girls because, despite certain stability in the prevalence of high BMI over the past 10 years, the heaviest boys are getting even heavier ${ }^{(24)}$. However, in most European countries trends in obesity have been consistent in boys and girls ${ }^{(20)}$.

There is little information about trends in underweight in European children. Data from Greek children suggested that the prevalence of underweight remained stable from 1997 through $2007^{(29)}$; data from children and adolescents in Tuscany, Italy, displayed an irregular trend $^{(15)}$; and data from 9-10-year-old schoolchildren in Liverpool, UK, also showed a fluctuating pattern in the period 1998-2006 ${ }^{(30)}$. Our work suggests that the trends in underweight prevalence may be easing off in Spanish children. Figure 1 supports that, unfortunately, the stabilization in the frequency of underweight in boys has been accompanied by increased adiposity, including in children with underweight. 

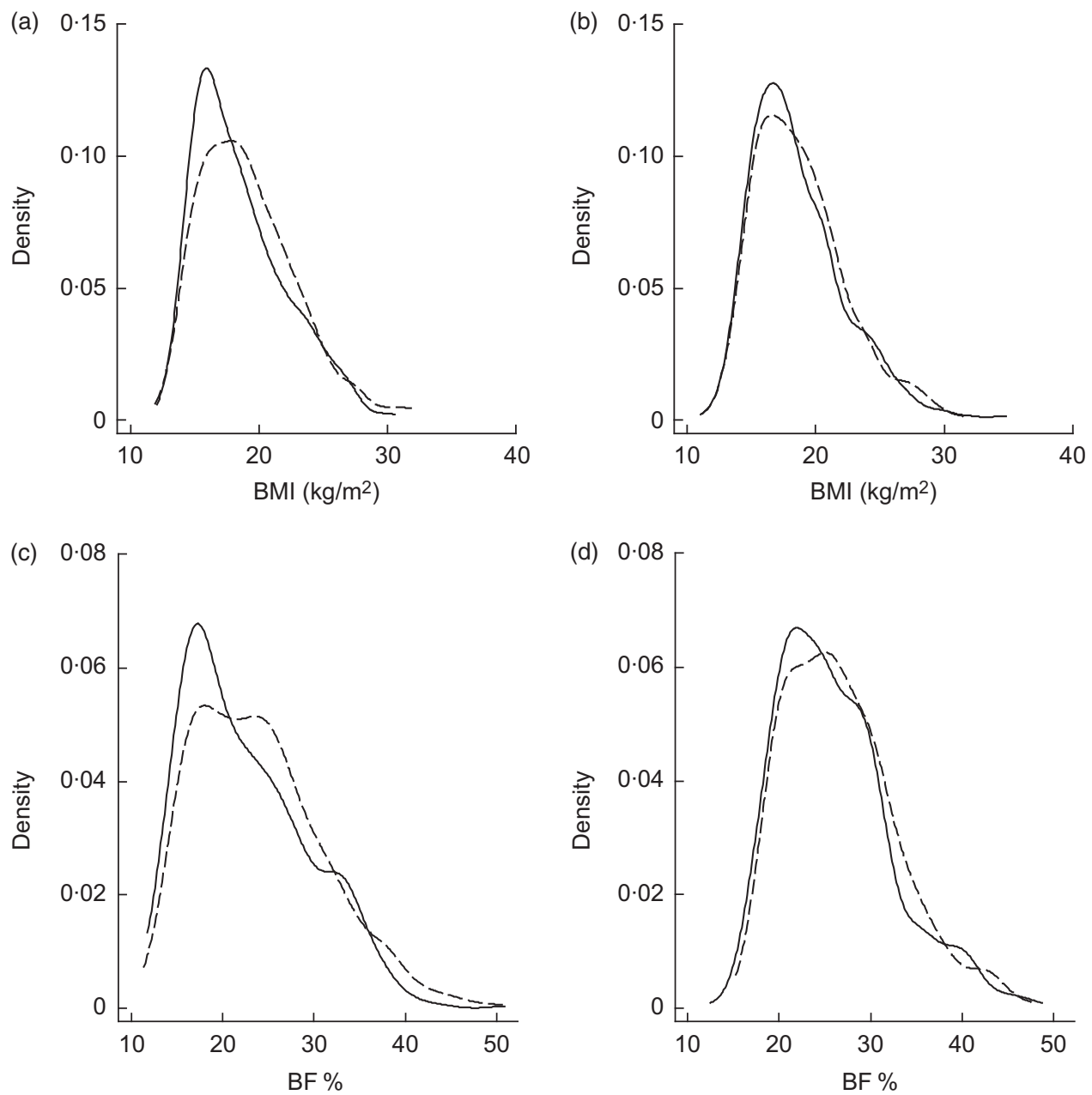

Fig. 1 Distribution of (a, b) BMI and (c, d) body fat percentage (BF\%) in 2004 (-) and $2010(---)$ among 8-11-year-old schoolchildren in Cuenca, Spain, by sex: $(a, c)$ boys and $(b, d)$ girls

A correct interpretation of our results requires some methodological comments. Because we only studied children aged 8-11 years in Cuenca, extrapolation of the results to other age groups and geographic settings should be done with caution. It is of note, however, that our analyses are based on data which are comparable over time in terms of population representativeness and measurement techniques, and are unique in Spain for examining trends in overweight and thinness among children. Furthermore, the prevalence of obesity in Cuenca is similar to that reported by other cross-sectional studies in different Spanish provinces whose data were collected at the same dates as ours $^{(3,4)}$. Otherwise, we have not measured the socioeconomic level of children's families and there is consistent evidence about the relationship between this variable and the prevalence of both overweight and underweight. We consider that this is a strong limitation in studies aimed to compare prevalence among regions or socio-economic groups, but is not an important limitation in the comparability of prevalence of underweight or overweight in the same Spanish town in a short time period.

\section{Conclusions}

The overweight epidemic in boys in Cuenca is still difficult to overcome. Moreover, despite the slowing in the progression of overweight and obesity prevalence in girls, the prevalence of excess weight in schoolchildren remains unacceptably high. Therefore, the current evidence-based efforts to halt the obesity epidemic in Spain should be strengthened.

\section{Acknowledgements}

This study was funded mainly by La Consejería de Sanidad de Castilla-La Mancha (grant GC03060-00). Additional funding was obtained from the Instituto de Salud Carlos III, Red de Investigación en Actividades Preventivas y de Promoción de Salud (grant RD06/0018/0038). There are no conflicts of interest to declare. V.M.-V. was the main researcher and guarantor. V.M.-V. and F.S.A. designed the study together with F.R.-A., who helped to refine the 
study design. V.M.-V. and F.S.A. coordinated data collection. B.N.P. made biochemical determinations. M.S.L., J.C.G.-P., C.T.N. and N.A.P. made anthropometry and adiposity determinations. M.S.M. conducted the statistical analysis and all authors contributed to the interpretation of results. V.M.-V. and F.R.-A. drafted the manuscript and all authors critically reviewed it for scientific content and approved the final version. The authors thank the schools, families and children for their enthusiastic participation in the study.

\section{References}

1. Lobstein T, Baur L \& Uauy R (2004) Obesity in children and young people: a crisis in public health. Obes Rev $\mathbf{5}$, $4-85$.

2. Martinez Vizcaino V, Salcedo Aguilar F, Franquelo Gutierrez R et al. (2006) Prevalence of obesity and trends in cardiovascular risk factors among Spanish school children, 1992-2004: the Cuenca (Spain) study. Med Clin 126, 681-685.

3. Alvarez Caro F, Díaz Martín JJ, Riaño Galán I et al. (2011) Classic and emergent cardiovascular risk factors in schoolchildren in Asturias. An Pediatr (Barc) 74, 388-395.

4. Serra-Majem L, Aranceta Bartrina J, Pérez-Rodrigo C et al. (2006) Prevalence and deteminants of obesity in Spanish children and young people. Br J Nutr 96, Suppl. 1, S67-S72.

5. Olds TS, Tomkinson GR, Ferrar KE et al. (2010) Trends in the prevalence of childhood overweight and obesity in Australia between 1985 and 2008. Int J Obes (Lond) 34, 57-66.

6. Ogden CL, Carroll MD, Kit BK et al. (2012) Prevalence of obesity and trends in body mass index among US children and adolescents, 1999-2010. JAMA 307, 483-490.

7. Aranceta J, Pérez-Rodrigo C, Serra-Majem L et al. (2007) Prevention of overweight and obesity: a Spanish approach. Public Health Nutr 10, 1187-1193.

8. Prentice AM \& Jebb SA (2001) Beyond body mass index. Obes Rev 2, 141-147.

9. Vizcaíno VM, Aguilar FS, Martínez MS et al. (2007) Association of adiposity measures with blood lipids and blood pressure in children aged 8-11 years. Acta Paediatr 96, 1338-1342.

10. Kolle E, Steene-Johannessen J, Holme I et al. (2009) Secular trends in adiposity in Norwegian 9-year-olds from 1999-2000 to 2005. BMC Public Health 14, 389.

11. Gutin B (2011) Diet vs exercise for the prevention of pediatric obesity: the role of exercise. Int J Obes (Lond) 35 , 29-32.

12. Martínez Vizcaíno V, Salcedo Aguilar F, Franquelo Gutiérrez $\mathrm{R}$ et al. (2008) Assessment of an after-school physical activity program to prevent obesity among 9- to 10-year-old children: a cluster randomized trial. Int J Obes (Lond) 32, 12-22.

13. Rudolf MC, Levine R, Feltbower $\mathrm{R}$ et al. (2006) The TRENDS Project: development of a methodology to reliably monitor the obesity epidemic in childhood. Arch Dis Child 91, 309-911.
14. Wang Y, Monteiro C \& Popkin BM (2002) Trends of obesity and underweight in older children and adolescents in the United States, Brazil, China, and Russia. Am J Clin Nutr $\mathbf{7 5}$, 971-977.

15. Lazzeri G, Rossi S, Pammolli A et al. (2008) Underweight and overweight among children and adolescents in Tuscany (Italy). Prevalence and short-term trends. J Prev Med Hyg 49, 13-21.

16. Martínez-Vizcaíno V, Sánchez López M, Moya Martínez P et al. (2009) Trends in excess weight and thinness among Spanish schoolchildren in the period 1992-2004: the Cuenca study. Public Health Nutr 12, 1015-1018.

17. Cole T, Bellizzi M, Flegal K et al. (2000) Establishing a standard definition for child overweight and obesity worldwide: international survey. BMJ 320, 1240-1243.

18. Cole TJ, Flegal KM, Nicholls D et al. (2007) Body mass index cut offs to define thinness in children and adolescents: international survey. BMJ 335, 194.

19. Jones MC, Linton $O \&$ Nielsen JP (1995) A simple bias reduction method for density estimation. Biometrika $\mathbf{8 2}$, 327-338.

20. Rokholm B, Baker JL \& Sørensen TIA (2010) The levelling off of the obesity epidemic since the year 1999 - a review of evidence and perspectives. Obes Rev 11, 835-846.

21. Devís-Devís J, Peiró-Velert C, Beltrán-Carrillo VJ et al. (2009) Screen media time usage of 12-16 year-old Spanish school adolescents: effects of personal and socioeconomic factors, season and type of day. J Adolesc 32, 213-231.

22. Vicente-Rodríguez G, Rey-López JP, Martín-Matillas M et al. (2008) Television watching, videogames, and excess of body fat in Spanish adolescents: the AVENA study. Nutrition 24, 654-662.

23. Rey-López JP, Vicente-Rodríguez G, Biosca M et al. (2008) Sedentary behaviour and obesity development in children and adolescents. Nutr Metab Cardiovasc Dis 18, 242-251.

24. Ogden CL, Carroll MD, Curtin LR et al. (2010) Prevalence of high body mass index in US children and adolescents, 2007-2008. JAMA 303, 242-249.

25. Moreno LA, Mesana MI, Fleta J et al. (2005) Overweight, obesity and body fat composition in Spanish adolescents. Ann Nutr Metab 49, 71-76.

26. Sjöberg A, Lissner L, Albertsson-Wikland $\mathrm{K}$ et al. (2008) Recent anthropometric trends among Swedish school children: evidence for decreasing prevalence of overweight in girls. Acta Paediatr 97, 118-123.

27. Sundblom E, Petzold M, Rasmussen F et al. (2008) Childhood overweight and obesity prevalences levelling off in Stockholm but socioeconomic differences persist. Int J Obes (Lond) 32, 1525-1530.

28. Stamatakis E, Zaninotto P, Falaschetti E et al. (2010) Time trends in childhood and adolescent obesity in England from 1995 to 2007 and projections of prevalence to 2015 . J Epidemiol Community Health 64, 167-174.

29. Tambalis KD, Panagiotakos DB, Kavouras SA et al. (2009) Eleven-year prevalence trends of obesity in Greek children: first evidence that prevalence of obesity is leveling off. Obesity (Silver Spring) 18, 161-166.

30. Boddy LM, Hackett AF \& Stratton G (2009) The prevalence of underweight in 9-10-year-old schoolchildren in Liverpool: 1998-2006. Public Health Nutr 12, 953-956. 